\title{
Effect of gamma-ray on some optical properties of polymetheylacrelate film (PMMA) doping with phenolphthalein (phph)
}

\author{
Ghaidaa J. Habi. \\ Departement of Physics, College of science, University of Kerbala, Kerbala, Iraq
}

\section{Article Info}

Received Jan 14, 2019

\section{Keywords:}

Polymetheylacrelate Polymer, Gamma Ray, optical Energy Gap, Absorbance and Extinction Coefficients, Phenolphthalein (phph).

\begin{abstract}
In this study, it has been investigated the effect of Gamma radiation on some optical characteristics of polymetheylacrelate (PMMA) polymer film specimens blended with $9 \%$ of phenolphthalein (phph), using casting technology and at room temperature conditions. The thickness of the prepared specimens were $(20 \pm 2) \mu \mathrm{m}$. The absorbance and transmission spectrum have been recorded in addition to their coefficients at range (299-1100) nm. The study has been reported absorbance and transmittance properties of the prepared samples and their coefficients, in addition to the optical gap energy for allowed and forbidden electronic transition. The study concluded that both absorbance and extinction coefficients are increasing proportionally with time of irradiation. While increasing time of exposure of gamma ray on the film layer of the prepared samples resulted in reduction of the optical gap energy property for allowed and forbidden electronic transition value.
\end{abstract}

\section{Corresponding Author:}

Ghaidaa Jabbar Habi.

Depratment of physics, College of Scinces, University of Kerbala, Karbala, Iraq

ghaidaa.j@uokerbala.edu.iq

\section{Introduction}

Polymetheylacrelate polymer (PMMA) considers as an important type of polymers because of its chemical and physical advantages. It is an anti-acid and anti-alkali substance. But unfortunately, it dissolves in some organic dissolvers such as toluene, kerosene, and chloroform liquids [1]. Additionally, the polymer behaves like solid material at ambient temperatures, and becomes elastic and deformable at higher temperatures. The optical transition of the polymer is about $102{ }^{\circ} \mathrm{C}$, it offers high transparency when subjected to the visible light ray, especially in case of wave lengths at range (100-360) $\mathrm{nm}[2,3]$. Such advantages enhanced the polymer to be used as an alternative option instead of normal glass in different applications such as in airplanes windows, homes windows, in manufacturing optical lens and prisms, in some complicated optical technologies and laboratories, and in production of Liquid crystals [4]. The Phenolphthalein substance, which denoted by (phph), and the Molecular formula of $\left(\mathrm{C}_{20} \mathrm{H}_{14} \mathrm{O}_{4}\right)$, is a colorless powder, dissolves in alcohol and ether, has a mass of $\left(318.32\right.$ g.mol $\left.{ }^{-1}\right)$ and density of $\left(1.277\right.$ g.cm $\left.{ }^{3}\right)$, and has melting point property of $\left(262.5^{\circ} \mathrm{C}\right)$ [5]. The effect of radiation on the polymer depends on its type. Some polymers particles suffer from dispersion and 
scattering if subjected to degradation process, and some others of polymers particles may collected and connected each to gather in cross linking process. Such processes may result in some changes of polymer optical characteristics, such as changing in color of polymer, higher absorbance, and reduction in extinction property value, which depends on type ray and radiation time [6].

\section{Expermental works}

The samples of PMMA film have been prepared using casting method. PMMA Samples those prepared as films, which has been supplied from Dentaurum German Company, are blended with $9 \%$ phph, which supplied from the General purpose reagent (BDH- Limited Poole England). The latter has degree of purity of 99.9\%. The procedure of mixing consisted of melting of (PMMA) polymer in chloroform substance first, then casting the mixture in a glass container to achieve polymer film of thickness $(20 \pm 2 \mathrm{~nm})$. Samples thickness have been measured using indirect micrometer $0.25 \mathrm{~nm}$ device with range $(0-100) \mu \mathrm{m}$. Additionally, the prepared mixture of (PMMA) polymer films doping with ( $\mathrm{phph}$ ) has been irradiation using the radiated source $\left(\mathrm{Cs}_{137}\right)$. This latter has (T1/2 of 30 year) and radiation activity of $\left(10^{-10} \mu \mathrm{ci}\right)$ during manufacture $(3 / 11 / 2005)$. Where the radiation activity of such substance is about $\left(7.405^{*} 10^{-10} \mu \mathrm{ci}\right)$. The geometric shape of the used radiant source was as disk overland directly on the tested specimens at distance $1 \mathrm{~mm}$ and for different time periods (24-120) hour.

Finally, the absorbance and extinction spectrums have been recorded using UV-Visible device, which manufactured by (Shimaduz), the Japanese company. The device is computerized to scan samples automatically for all wave lengths. Absorbance and extinction spectrums were measured at lengths ranged between $(299-1100 \mathrm{~nm})$.

\section{Results and discussion}

Figure 1 represents the relationship between the Absorption and wave length for the (PMMA) specimens film blended with (phph), before and after irradiation and for different time periods. It can be observed that maximum value of absorbance occurs at wave length $(299 \mathrm{~nm})$. On the other hand, the new mixture behave as a transparency substance at higher wave lengths. According to blank theory, increasing wave length results in decreasing light energy, and hence the absorbance property decreased. It worth to be mentioned that absorbance property becomes higher than its value after irradiation [7].

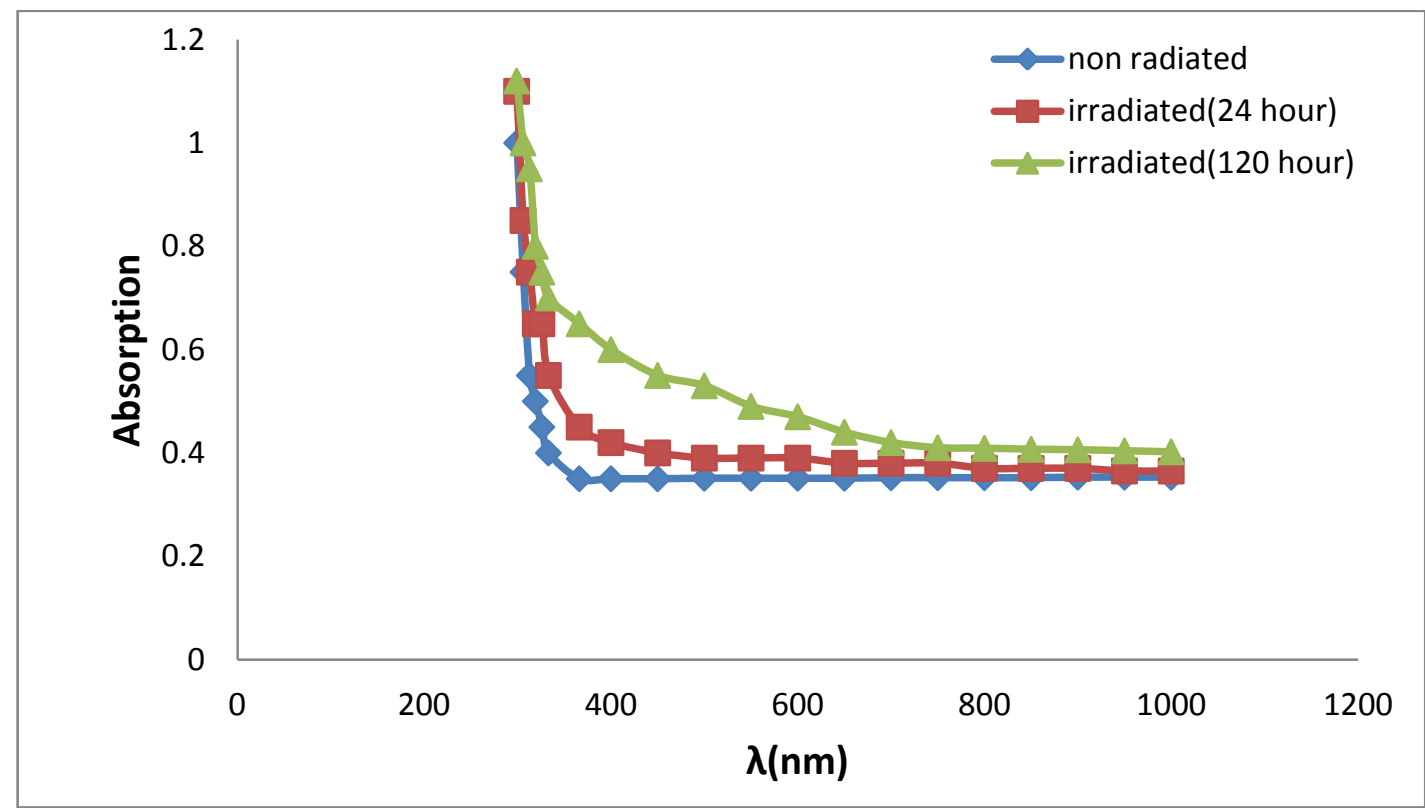

Figure 1. Relation between the Absorption and wave length before and after irradiation

Figure 2 illustrates the relation between transmittance property and wave length of films, before and after irradiation and for different time periods. It has been found that transmittance values become less before irradiation [7]. 


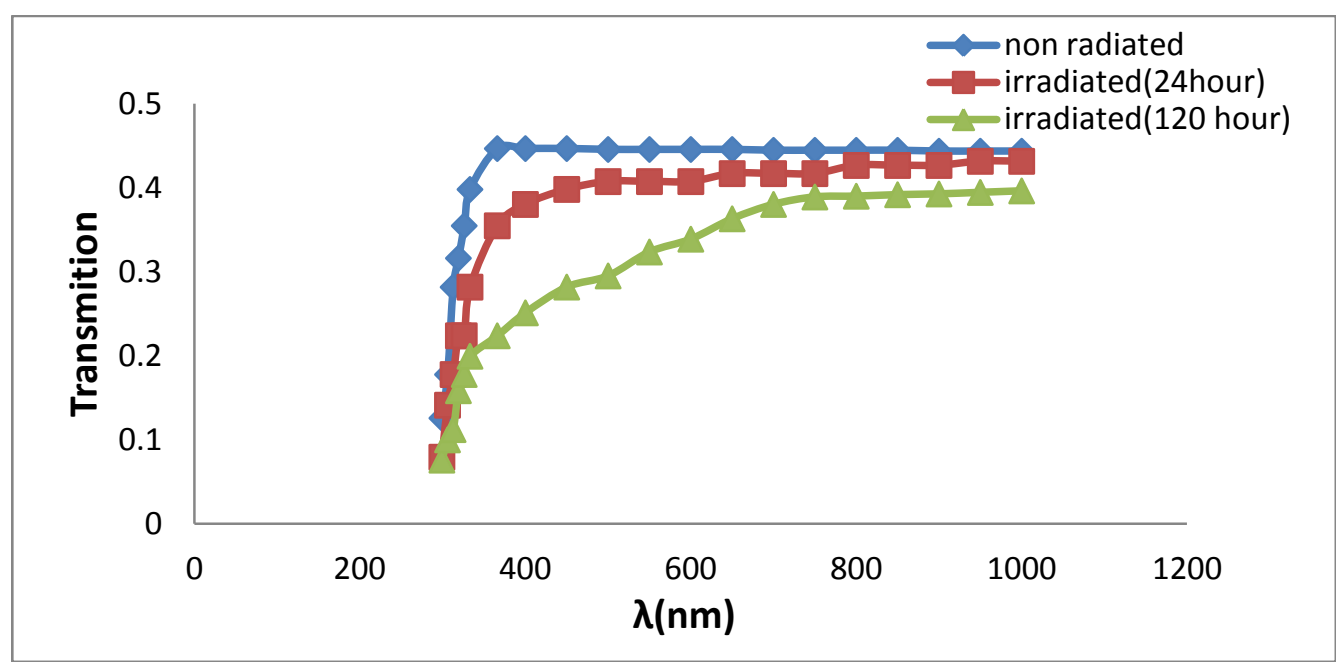

Figure 2. Relation between Transmition property and wave length before and after irradiation.

Figure (3) represents the relation between absorbance coefficient and photon energy of (PMMA) specimens films blended with ( $\mathrm{phph}$ ), before and after irradiation and for different time periods. When absorbance coefficients are high $\left(\alpha>104 \mathrm{~cm}^{-1}\right)$, electronic transitions become direct. While for values lower than $104 \mathrm{~cm}$ 1 , the electronic transitions become indirect [8].

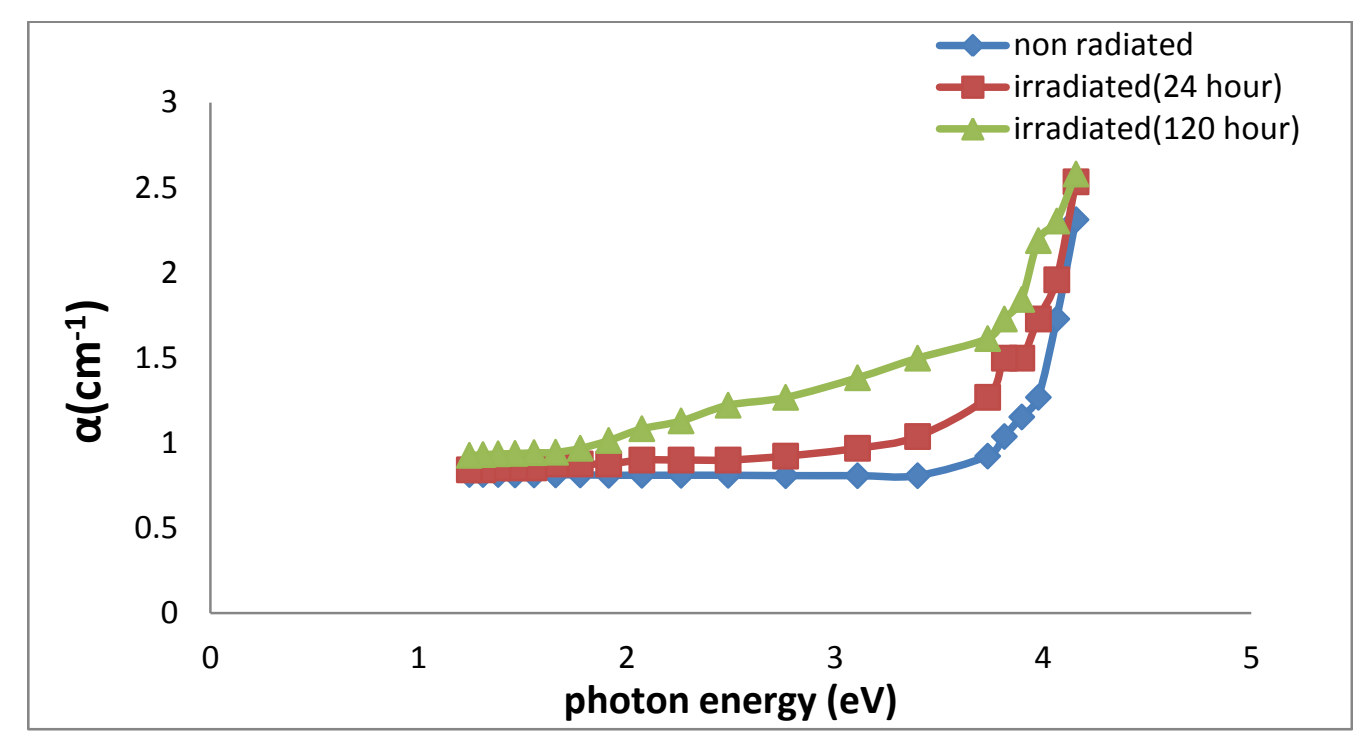

Figure 3. The relation between the absorbance coefficient and photon energy before and after irradiation.

From Figure (3), it can be also observed from the obtained results that absorbance values were less than (104 $\mathrm{cm}-1$ ), which means that the electronic transitions was indirect, and absorbance property was clearly increasing due to the effect of irradiation, and such results go with the results of reference [9]. Absorbance values have been calculated using the following formula [10]:

Where, $\mathrm{d}$ is the film thickness.

$$
\alpha=2.303 \quad \mathrm{~A} / \mathrm{d}
$$

Figure (4) represents the relation between extinction coefficient and wave length of the prepared specimens, before and after irradiation and for different time periods. it can be noticed from the figure that increasing extinction coefficient values resulted in increasing wavelength. Extinction coefficient values after irradiation, 
become higher than before the process, and this is agree with the results of reference [11].It worth to be mentioned that extinction coefficient $(\mathrm{K})$ values were calculated using the following formula [12] :

$$
\mathrm{K}=\alpha \lambda / 4 \pi
$$

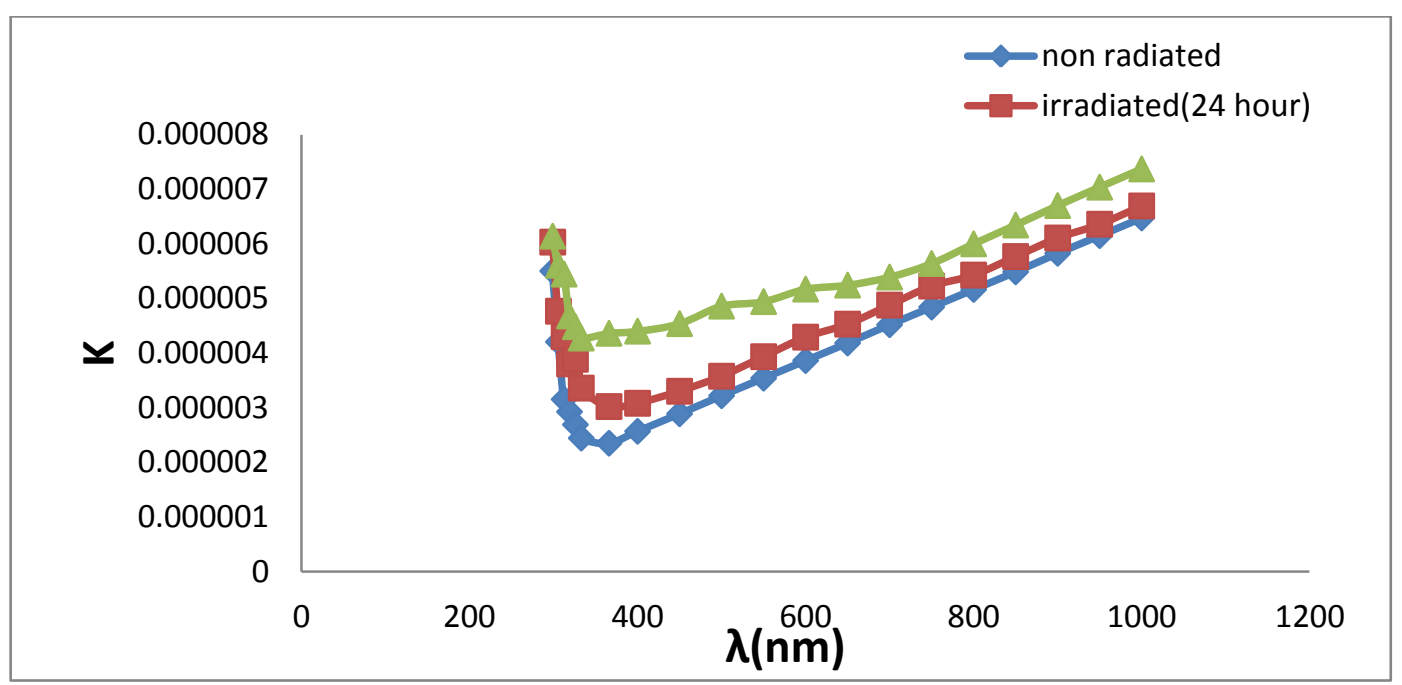

Figure 4. Relation between the extinction coefficient and wave length before and after irradiation

The forbidden energy gap of indirect transition both allowed, forbidden calculated according to the relationship [13]:

Where,

$$
\alpha h v=A(h v-E g) m
$$

ho is the energy of photon,

A is proportionality constant,

Eg is forbidden energy gap of the indirect transition.

If the value of $(m=2)$ indicates to allowed indirect transition .when the value $(m=3)$ indicates to forbidden indirect transition.

Figures $(5,6$, and 7$)$ illustrate the relation between $(\alpha h v)^{1 / 2}$ and photon energy of the prepared specimens before and after irradiation and for different time periods. Form Figure (5), it can be observed that the Optical gap energy for the allowed indirect transition of the specimens is $(2.55 \mathrm{eV})$, and becomes $(2.35 \mathrm{eV})$ after irradiation for a period of (24 hour), as clarified in Figure (6). While this value becomes $(2.22 \mathrm{eV})$ after irradiation for a period of (120 hour), as can be seen in Figure (7).

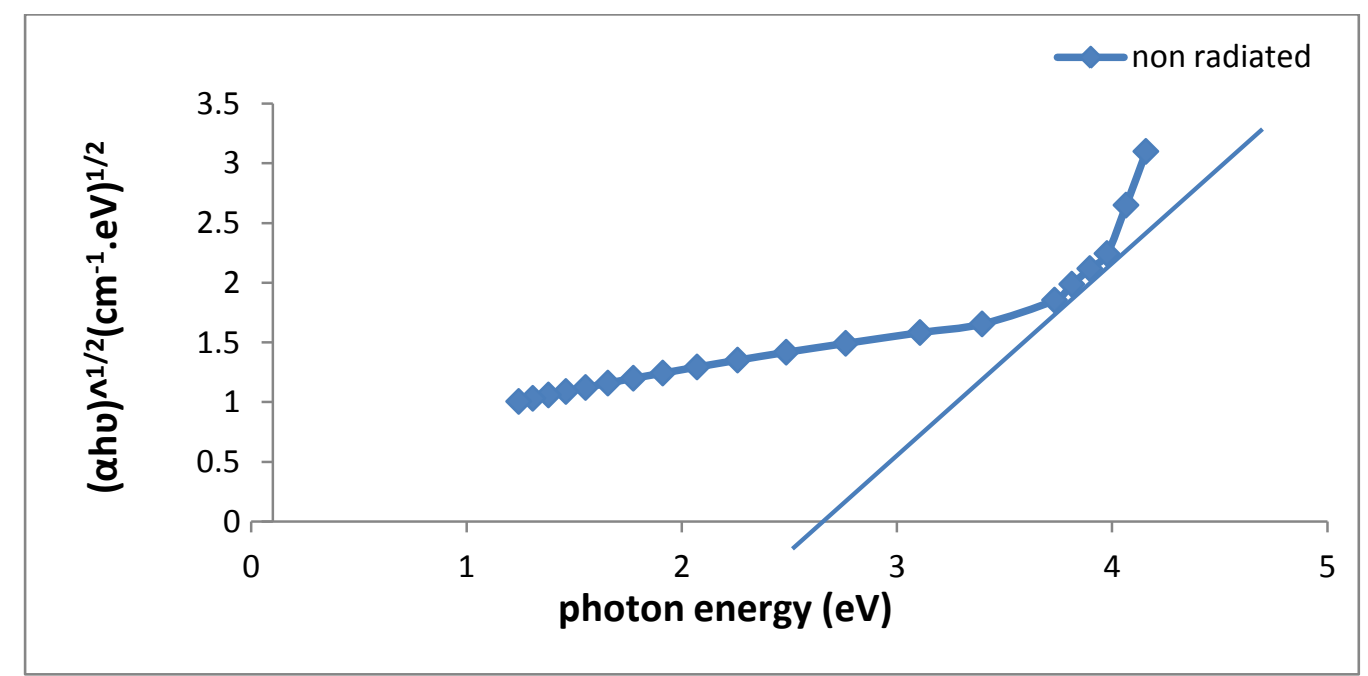

Figure 5. The relation between the $(\alpha \mathrm{h} v)^{1 / 2}$ and photon energy before irradiation. 


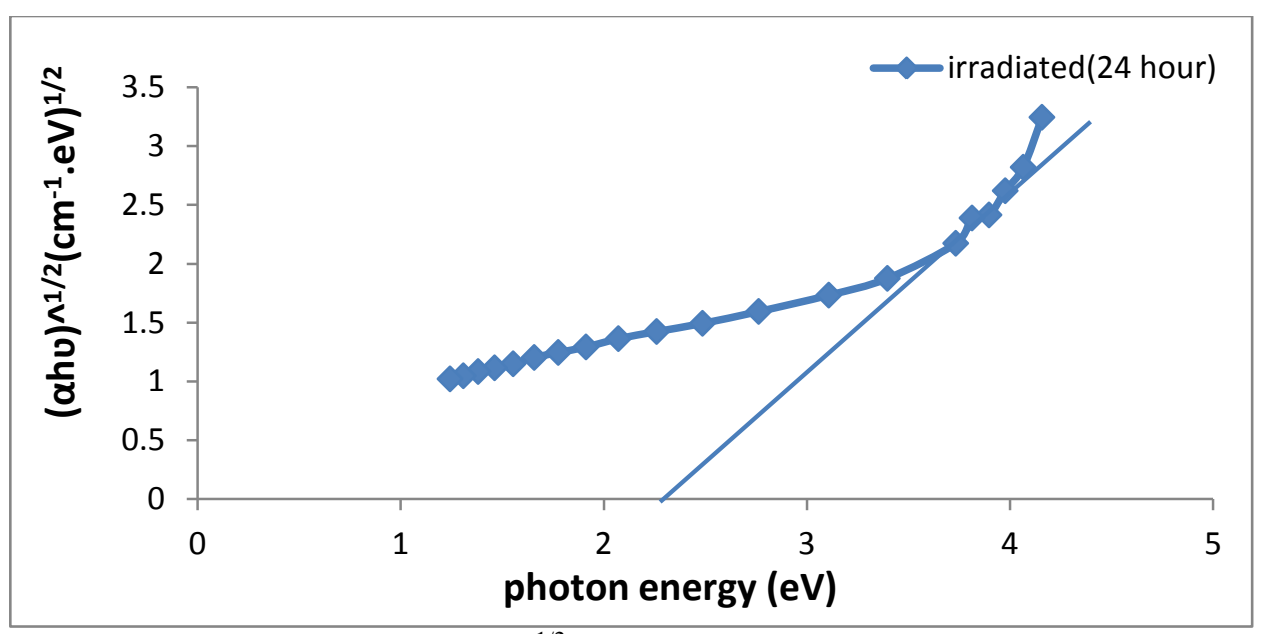

Figure 6. The relation between the $(\alpha h v)^{1 / 2}$ and photon energy after irradiation for a period of 24 hour.

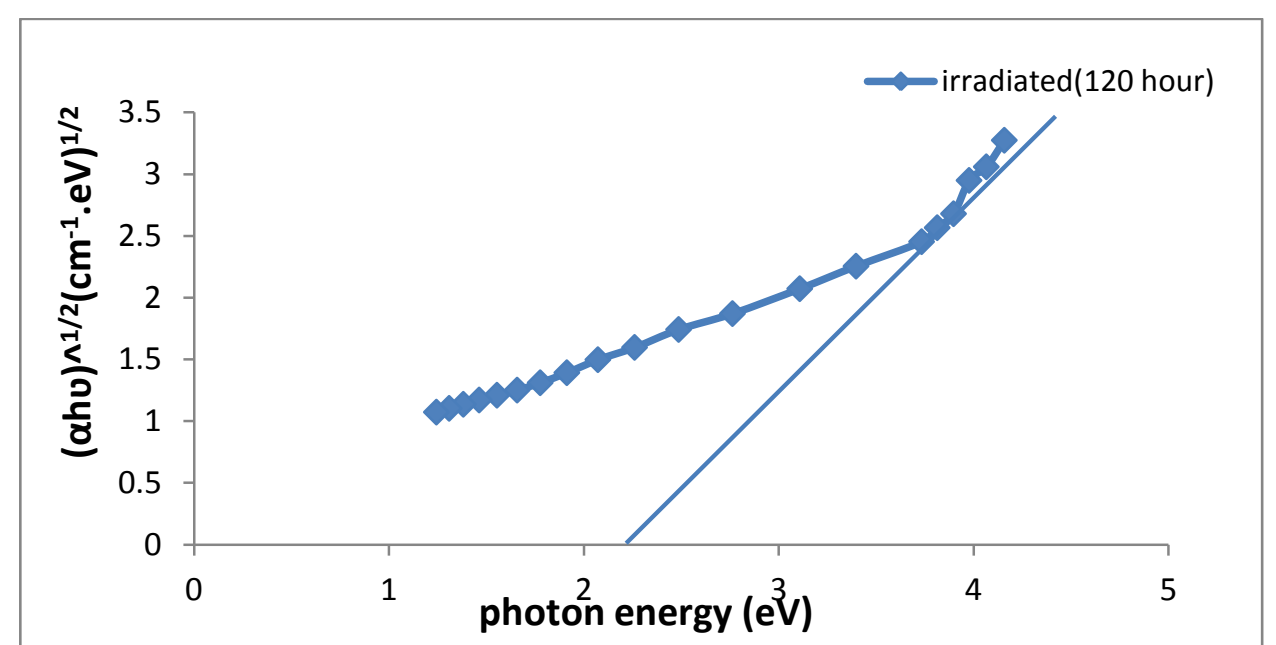

Figure 7. The relation between the $(\alpha h v)^{1 / 2}$ and photon energy after irradiation for a period of 120 hour.

Figures $(8,9$, and 10) clarify the relation between $(\alpha \mathrm{h} v) 1 / 3$ and photon energy for films before and after coating process. Form Figure (8), it can be observed that the optical gap energy of the allowed indirect forbidden transition of the films is about $(2.3 \mathrm{eV})$, and becomes $(2.1 \mathrm{eV})$ after irradiation for a period of $(24$ hour), as clarified in Figure (9). While this value becomes $(2 \mathrm{eV})$ after irradiation for a period of (120 hour), as can be seen in Figure (10) and such results go with the results of reference [14-16].

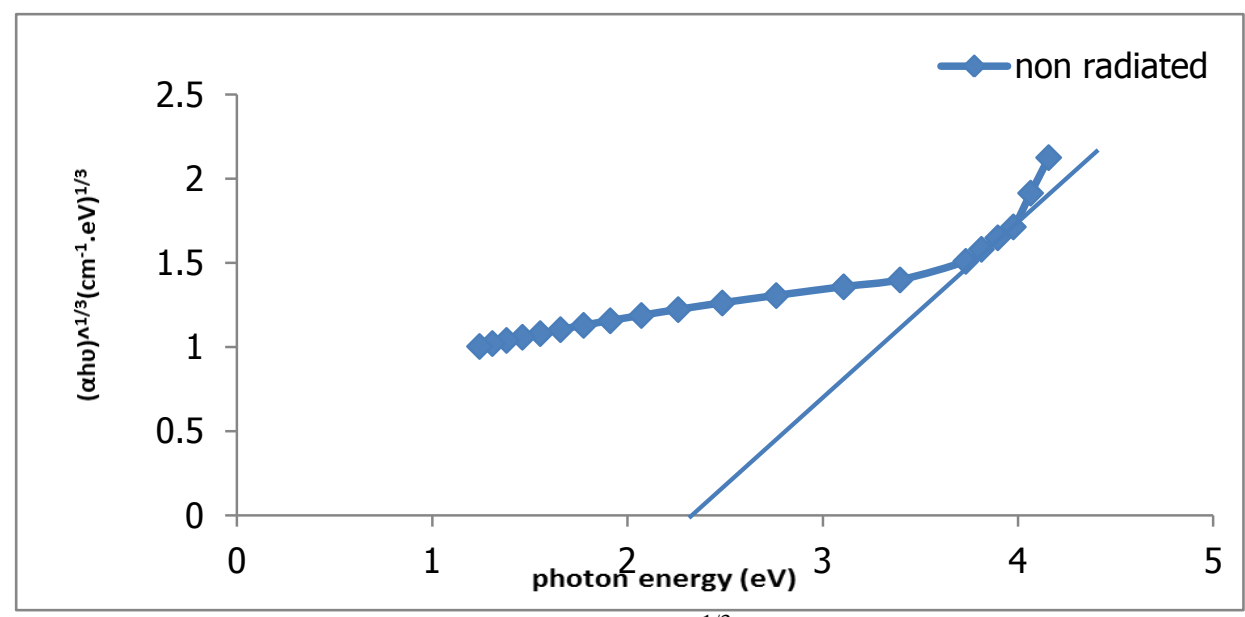

Figure 8 . The relation between the $(\alpha h v)^{1 / 3}$ and photon energy before irradiation. 


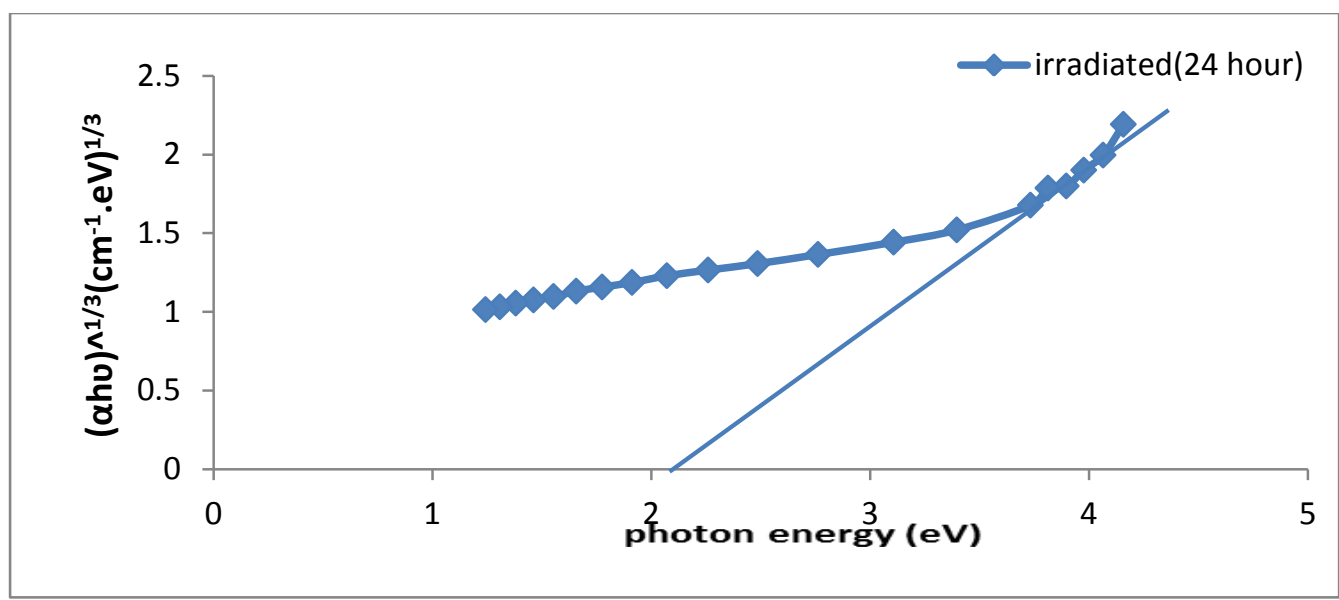

Figure 9. The relation between the $(\alpha h v)^{1 / 3}$ and photon energy after irradiation for a period of 24 hour.

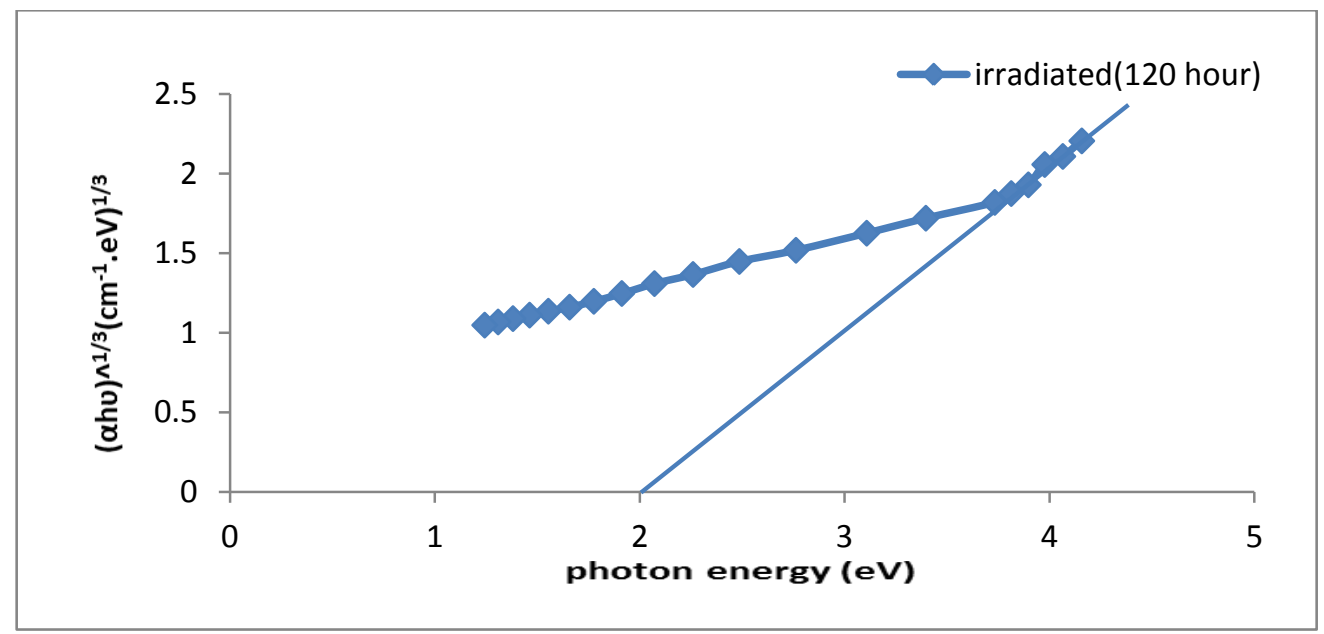

Figure 10. The relationship between the $(\alpha h v)^{1 / 3}$ and photon energy after irradiation for a period of 120 hour.

\section{Conclusions}

From the previous works, the researcher has concluded that irradiation (PMMA) polymer that blended with (phph) resulted in increasing absorbance property, because of some changes in polymer structure. Irradiation process led to enhance bonding between polymer chains. While in case of absorbance coefficient values, they were less than (104 cm-1), which means that the indirect allowed and forbidden electronic transitions have occurred successfully. Finally, for the obtained values of extinction coefficients, they were higher after irradiation process when compared before the process. Additionally, it has been concluded that the values of optical gap energy of allowed and forbidden indirect transition decreased due to the effect of irradiation process.

\section{References}

[1] Ballato J.,"Novel polymeric optical fibers amplifiers and lasers", National textile center research Briefs Materials competency, 2003.

[2] Oss Wald, T.A.,"polymer processing Fundamentals", Hauser pubs. , Munich, 1998.

[3] Harman, F.M.,"Encyclopedia of polymer science and Engineering", 2nd Ed, .15, PP. 377-397, 1976.

[4] Sinth Archeic P., Material Research society Symp., Vol.629, 2002.

[5] June K. Dunnick and James R. Hailey,"Phenolphthalein Exposure causes Multiple Carcinogenic Effects in Experimental Model Systems ", Cancer Research 56(21):4922-4926, November 1, 1996. 
[6] Dhameer A. Mutlak, "Gamma Irradiation Effects on some physical properties of polymer composites", Ph.D. Thesis, Baghdad university, 2007.

[7] Ali H. , "Dopping effect on optical constant of polymethylacrelate (PMMA) dopping with phenolphthalein", Journal of Babylon university, Pure \&Applied Sciences, No. 4, Vol. 21 , 2013.

[8] B. 1. deng, y. s. hu, y. chiu, 1. w. Chen, Y. S. Chiu, polym. Degrade. Stab, Vol. 57, PP. 269, 2003.

[9] Alia H. , Mohammed S. , Mohammed H. , "Study the effect of Gamma radiation on the optical energy gap of polymetheylacrelate (PMMA)", Diyala Journal for Pure Sciences, Vol. 6 , No. 4 , October , 2010 .

[10] M. O. H. Cioffi, H. J. C. Vorwald, R. P. Mota, Mater. Charact. , Vol.50, PP. 209, 2003.

[11] K. Rashid, "The effects of the optical properties on the (PMMA) Puerty", Ibn AL-Haitham Journal for Pure \&Appl. Sci. Vol.23 (3), 2010.

[12] Ahmed A. H., Awatif A. M., and Zeid Abdul Majied, "Dopping effect on optical constant of polymethylmethacrylate (PMMA)", Eng. And Technology, Vol.25, No.4, 2007.

[13] Kathalingam. A. et al, "Materials Chemistry and physics", Vol. 106, No. 215, 2007.

[14] Nader F. , Ali T. , Rushdie A. , " Electronic transfers of polymethylmethacrylate (PMMA) Dioxide of iron chloride (FeCl2)" , Mustansiriya University , Journal of college of education , No.1 , 2010 .

[15] B. Durakovic, "Design of Experiments Application, Concepts, Examples: State of the Art," Periodicals of Engineering and Natural Scinces, vol. 5, no. 3, p. 421-439, 2017.

[16] B. Duraković and S. Mešetović, "Thermal Performances of Glazed Energy Storage Systems with Various Storage Materials: An Experimental study," Sustainable Cities and Society, vol. 45, no. February, pp. 422-430, 2019. 